\title{
Wide-range-adjusted threshold voltages for E-mode AIGaN/GaN HEMT with a p-SnO cap gate
}

\author{
Dazheng Chen ${ }^{1 \dagger^{*}}$, Peng Yuan ${ }^{1 \dagger}$, Shenglei Zhao ${ }^{1}$, Shuang Liu ${ }^{1}$, Qian Xin ${ }^{2}$, Xiufeng Song${ }^{1}$, Shiqi Yan ${ }^{2}$, \\ Yachao Zhang ${ }^{1}$, He Xi ${ }^{1}$, Weidong Zhu' ${ }^{1}$, Weihang Zhang ${ }^{1}$, Jiaqi Zhang ${ }^{1}$, Hong Zhou ${ }^{1}$, Chunfu Zhang ${ }^{1}$, \\ Jincheng Zhang ${ }^{1 *}$ and Yue $\mathrm{Hao}^{1}$
}

\begin{abstract}
GaN cap layer has been recognized as a commercial technology to manufacture enhanced-mode (E-mode) AlGaN/GaN high electron mobility transistor (HEMT); however, the difficult activation of Mg doping and etching damage of $\mathrm{p}$-GaN limit the further improvement of device performance. Thus, the more cost-effective cap layer has attracted wide attention in GaN-based HEMT. In this paper, $p$-type tin monoxide ( $\mathrm{p}$-SnO) was firstly investigated as a gate cap to realize E-mode AlGaN/GaN HEMT by both Silvaco simulation and experiment. Simulation results show that by simply adjusting the thickness ( 50 to $200 \mathrm{~nm}$ ) or the doping concentration $\left(3 \times 10^{17}\right.$ to $\left.3 \times 10^{18} \mathrm{~cm}^{-3}\right)$ of $\mathrm{p}$-SnO, the threshold voltage $\left(V_{\text {th }}\right)$ of HEMT can be continuously adjusted in the range from zero to $10 \mathrm{~V}$. Simultaneously, the device demonstrated a drain current density above $120 \mathrm{~mA} \mathrm{~mm}^{-1}$, a gate breakdown voltage $\left(V_{\mathrm{BG}}\right)$ of $7.5 \mathrm{~V}$ and a device breakdown voltage $\left(V_{B}\right)$ of $2470 \mathrm{~V}$. What is more, the etching-free AlGaN/ GaN HEMT with sputtered p-SnO gate cap were fabricated, and achieved a positive $V_{\text {th }}$ of $1 \mathrm{~V}, V_{\mathrm{BG}}$ of $4.2 \mathrm{~V}$ and $V_{\mathrm{B}}$ of $420 \mathrm{~V}$, which confirms the application potential of the p-SnO film as a gate cap layer for E-mode GaN-based HEMT. This work is instructive to the design and manufacture of p-oxide gate cap E-mode AlGaN/GaN HEMT with low cost.
\end{abstract}

Keywords: p-SnO gate cap, E-mode AlGaN/GaN HEMT, positive threshold voltage, wide-range adjustment, silvaco ATLAS, sputtered $\mathrm{p}-\mathrm{SnO}$

\section{INTRODUCTION}

Owing to the great advantages of large bandgap width, high breakdown field intensity, high polarization coefficient, high electron mobility, and saturated electron drift velocity [1,2], gallium nitride $(\mathrm{GaN})$ heterostructures have been used in high electron mobility transistors (HEMTs) and found wide applications in power electronics. But the difficulty to realize enhanced-mode (E-mode) operation has become one of the key factors which limit their large-scale commercialization [3]. At present, the main solutions include recess gate structure [4], fluoride plasma treatment [5], p-type GaN (p-GaN) gate [6-10], and Cascode structure [11]. Among them, only the p-GaN gate has been proved as a promising strategy in practical application. However, the threshold voltage $\left(V_{\mathrm{th}}\right)$ in $\mathrm{p}-\mathrm{GaN}$ gate devices is relatively low (around $1 \mathrm{~V}$ ) [12], which is due to that the $\mathrm{Mg}$ doping in $\mathrm{GaN}$ is difficult to be activated and thus the low hole concentration may limit the further increase of $V_{\text {th }}$. Also the dry etching-induced damage would deteriorate the electrical characteristics and reliability of AlGaN/GaN HEMT [13].

In recent years, p-type metal-oxides $\left(\mathrm{NiO}, \mathrm{Cu}_{2} \mathrm{O}\right.$, etc. $)$ have been used to fabricate E-mode AlGaN/GaN HEMT due to their high hole concentration and compatibility to wet etch process. Nevertheless, the $V_{\text {th }}$ of HEMT with $\mathrm{p}-\mathrm{NiO}$ and $\mathrm{p}-\mathrm{Cu}_{2} \mathrm{O}$ gate cap was generally around zero volt [14-18]. As we know, the principle of $\mathrm{p}-\mathrm{GaN}$ cap to achieve E-mode operation lies in that, at zero bias voltage, the bottom of conduction band $\left(E_{\mathrm{c}}\right)$ can be raised above the Fermi level $\left(E_{\mathrm{f}}\right)$ of $\mathrm{GaN}$ to exhaust the twodimensional electron gas (2DEG) under the gate. Unlike the conventional HEMT devices, the $V_{\text {th }}$ of p-gate cap devices is related to the depth of the valence-band-top $\left(E_{\mathrm{v}}\right)$ rather than the $E_{\mathrm{c}}$ [19]. Due to the relatively low $E_{\mathrm{v}}$ levels of $\mathrm{NiO}$ or $\mathrm{Cu}_{2} \mathrm{O}$ $(\sim 5.4 \mathrm{eV})$, the limited uplift ability of energy level at the AlGaN/ GaN interface becomes an obstacle to obtain positive $V_{\text {th }}$ in $\mathrm{p}$ gate cap HEMTs. Therefore, a p-type oxide with sufficient $E_{\mathrm{v}}$ depth may be favorable for achieving E-mode GaN-based HEMT, but the further systematic investigation is lacking.

In this study, the AlGaN/GaN HEMTs with $\mathrm{p}-\mathrm{SnO}\left(E_{\mathrm{v}} \approx\right.$ $7.6 \mathrm{eV})$ and other oxide $\left(E_{\mathrm{v}}>5.4 \mathrm{eV}\right)$ gate caps have been systematically investigated by using the ATLAS in Silvaco TCAD and reported experimental parameters. As $\mathrm{p}$-SnO film possesses large electron affinity, wide bandgap [20], high p-doping concentration $\left(5 \times 10^{18} \mathrm{~cm}^{-3}\right)$, various deposition methods (sputter, e-beam, pulsed laser deposition, etc.) [21-24], and low treatment temperature, it has been successfully applied to $\mathrm{p}$-channel thin film transistors (TFTs), $\mathrm{p}-\mathrm{n}$ junctions, complementary metal oxide semiconductor (CMOS) logic circuits, and transparent devices $[21,25,26]$. Here, the simulation results showed that the $V_{\text {th }}$ of AlGaN/GaN HEMT can be wide-range-controlled from zero to $10 \mathrm{~V}$ by simply adjusting the thickness (50 to $200 \mathrm{~nm}$ ) or the doping concentration $\left(3 \times 10^{17}\right.$ to $\left.3 \times 10^{18} \mathrm{~cm}^{-3}\right)$ of $\mathrm{p}-\mathrm{SnO}$. The device also demonstrated a drain current density above $120 \mathrm{~mA} \mathrm{~mm}^{-1}$, a gate breakdown voltage $\left(V_{\mathrm{BG}}\right)$ of $7.5 \mathrm{~V}$ and a device breakdown voltage $\left(V_{\mathrm{B}}\right)$ over $2 \mathrm{kV}$. Further, the feasibility

\footnotetext{
${ }^{1}$ State Key Discipline Laboratory of Wide Bandgap Semiconductor Technology, School of Microelectronics, Xidian University, Xi'an 710071, China

2 State Key Laboratory of Crystal Materials, Center of Nanoelectronics and School of Microelectronics, Shandong University, Jinan 250100, China

$\dagger$ These authors contributed equally to this work.

* Corresponding authors (emails: dzchen@xidian.edu.cn (Chen D); jchzhang@xidian.edu.cn (Zhang J))
} 
of $\mathrm{p}$-SnO gate cap has been experimentally verified. This work is instructive to the manufacture of cost-effective E-mode HEMT and the development of GaN-based power electronics.

\section{METHOD}

In order to ensure the reliability and accuracy, the model has been calibrated according to the report of gate injection transistor by Uemoto et al. in 2007 [27]. As shown in Fig. 1a, when the gate voltage $\left(V_{\mathrm{G}}\right)$ is $6 \mathrm{~V}$, the drain current density reaches $260 \mathrm{~mA} \mathrm{~mm}^{-1}$ in the transfer curve, and the $V_{\text {th }}$ is $1 \mathrm{~V}$. In the output curves (inset in Fig. 1a), the drain saturation current density reaches $200 \mathrm{~mA} \mathrm{~mm}^{-1}$ when the $V_{\mathrm{G}}$ is set as $5 \mathrm{~V}$. Both of them agree well with the reference. After model calibrating, the basic characteristics of AlGaN/GaN HEMT (Fig. 1b) with p-SnO and other oxide (such as $\mathrm{Cu}_{2} \mathrm{O}, \mathrm{NiO}, \mathrm{WO}_{3}, \mathrm{MoO}_{3}$, and $\mathrm{V}_{2} \mathrm{O}_{5}$ ) gate caps have been simulated by ATLAS in Silvaco TCAD. In details, the structure of $\mathrm{p}$-SnO gate cap HEMT consists of a substrate ( $\mathrm{Si}, \mathrm{SiC}$, or sapphire), $3 \mu \mathrm{m} \mathrm{GaN} \mathrm{semi-insulating} \mathrm{layer,}$ $200 \mathrm{~nm} \mathrm{GaN}$ channel layer, $20 \mathrm{~nm} \mathrm{Al}_{0.2} \mathrm{Ga}_{0.8} \mathrm{~N}$ barrier layer, $150 \mathrm{~nm}$ p-SnO layer, and $\mathrm{Si}_{3} \mathrm{~N}_{4}$ passivation layer. The gatesource length $\left(L_{\mathrm{GS}}\right)$, gate length $\left(L_{\mathrm{G}}\right)$, gate width $\left(W_{\mathrm{G}}\right)$, and gatedrain length $\left(L_{\mathrm{GD}}\right)$ are $2.5,5,50$, and $11.5 \mu \mathrm{m}$, respectively. Here the influence of the thickness, doping concentration, bandgap of p-SnO on the $V_{\text {th }}$, and the underlying mechanism have been studied. The detail calculation method can be found in our previous work [28], and all the parameters including bandgap, dielectric constants, electron affinity, $E_{\mathrm{v}}$ and $E_{\mathrm{c}}$ for oxides come from the experimental reports [14,29-32].

\section{RESULTS AND DISCUSSION}

\section{Basic characteristics of $\mathrm{p}$-SnO gate cap HEMT}

The $V_{\text {th }}$ of AlGaN/GaN HEMT is generally defined as the gate bias voltage when the drain current density reaches $1 \mathrm{~mA} \mathrm{~mm}^{-1}$ under $10 \mathrm{~V}$ drain voltage $\left(V_{\mathrm{D}}\right)$. As shown in Fig. $2 \mathrm{a}$, the $\mathrm{p}-\mathrm{SnO}$ gate cap HEMT has obtained a positive $V_{\text {th }}$ of $3.2 \mathrm{~V}$, which reveals the E-mode operation of HEMT and the value of $V_{\text {th }}$ could meet the requirements of power applications. Especially, a doping concentration as high as $2 \times 19 \mathrm{~cm}^{-3}$ of $\mathrm{p}-\mathrm{GaN}$ is necessary to realize E-mode HEMT [33], while here a much lower doping concentration of $7 \times 17 \mathrm{~cm}^{-3}$ for $\mathrm{p}$-SnO is enough and this $\mathrm{p}$-SnO film could be easily achieved by several deposition methods at a lower cost. From Fig. 2b, the saturation drain current density of the device can reach $120 \mathrm{~mA} \mathrm{~mm}^{-1}$ when $V_{\mathrm{G}}=8 \mathrm{~V}$, and the specific on-resistance $\left(R_{\mathrm{ON}}\right)$ [34] is about $3.8 \mathrm{~m} \Omega \mathrm{cm}^{2}$. In Fig. $2 \mathrm{c}$, under a $V_{\mathrm{G}}$ of zero and drain current density of $1 \mathrm{~mA} \mathrm{~mm}^{-1}$, the $V_{\mathrm{B}}$ can reach $2470 \mathrm{~V}$. Therefore, besides the more positive $V_{\text {th }}$, the basic performance of $\mathrm{p}$-SnO gate cap HEMT can also satisfy the needs of practical applications.

Meanwhile, the gate leakage current and breakdown characteristics of $\mathrm{AlGaN} / \mathrm{GaN}$ HEMTs with the $\mathrm{p}-\mathrm{SnO}$ or $\mathrm{p}-\mathrm{GaN}$ gate caps have been simulated. It is clear the gate leakage current density in $\mathrm{p}$-SnO gate cap HEMT is much lower than that in $\mathrm{p}$ GaN device (inset in Fig. 2d). This can be explained by the behaviors of the schottky diode (gate-metal/p-cap) and PIN diode (p-cap/AlGaN/GaN). The schottky diode is reverse-cut off when a positive $V_{\mathrm{G}}$ is applied, and the PIN diode will be turned off at a negative $V_{\mathrm{G}}$ and the depletion region will expand, both of which could act as a blocker of gate leakage current [35]. Due to the deeper $E_{\mathrm{v}}$ of $\mathrm{p}-\mathrm{SnO}$ than $\mathrm{p}-\mathrm{GaN}$, the relatively high schottky barrier is thus responsible for the lower gate leakage current in corresponding devices. On the other hand, the gate breakdown voltage is another key parameter to HEMT. Under a $V_{\mathrm{D}}$ of zero and gate current density of $1 \mathrm{~mA} \mathrm{~mm}^{-1}$, the extracted gate breakdown voltage of $\mathrm{p}$-SnO device $(7.5 \mathrm{~V})$ is also higher than that of the p-GaN device $(6 \mathrm{~V})$, as shown in Fig. $2 \mathrm{~d}$.

\section{$V_{\text {th }}$ regulation of p-SnO gate cap HEMT}

For p-SnO HEMT in Fig. 3a, with the increase of SnO thickness from 50 to $200 \mathrm{~nm}$ or the doping concentration of $\mathrm{SnO}$ from $3 \times$ $10^{17}$ to $3 \times 10^{18} \mathrm{~cm}^{-3}$, the $V_{\text {th }}$ of AlGaN/GaN HEMT can be controlled in a large range from 0 to $10 \mathrm{~V}$. Typically, it can be seen from Fig. $3 b$ that the $V_{\text {th }}$ are $0,1.2,2.4,3.6,4.8,6.1$, and $7.3 \mathrm{~V}$ when the doping concentration of $\mathrm{p}$-SnO locates between $4 \times 10^{17}$ and $1 \times 10^{18} \mathrm{~cm}^{-3}$. Similarly, the increased $V_{\text {th }}(0.5,1.5$, $2.8,4.5,6.4$, and $8.6 \mathrm{~V}$ ) can be obtained in Fig. $3 \mathrm{c}$ when the thickness of p-SnO changes from 100 to $200 \mathrm{~nm}$. As a result, the $V_{\text {th }}$ can be wide-range-controlled by simply adjusting the thickness or doping concentration of $\mathrm{p}-\mathrm{SnO}$, which is favorable to the fabrication of power devices.

To understand the physical mechanism, Fig. $3 \mathrm{~d}$ shows the energy band diagrams in the gate region of $\mathrm{p}$-SnO HEMT at the SnO doping concentrations of $6 \times 10^{17}, 8 \times 10^{17}, 1 \times 10^{18}$ and $2 \times$ $10^{18} \mathrm{~cm}^{-3}$. For the PIN diode (p-SnO/AlGaN/GaN), it is well known in the pn junction theory that the depletion width in $\mathrm{p}$ $\mathrm{SnO}$ decreases with its doping concentration, while the depletion region in the GaN side will expand accordingly. This means that
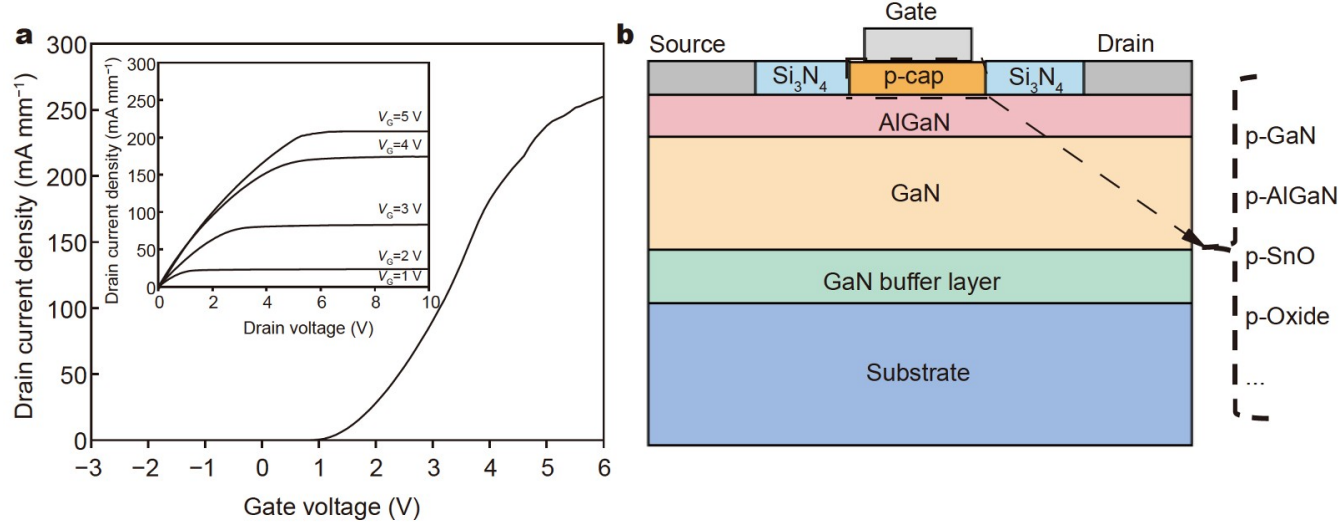

Figure 1 Simulated (a) transfer and output curves in model calibrating, and (b) device structure of p-cap AlGaN/GaN HEMT. 

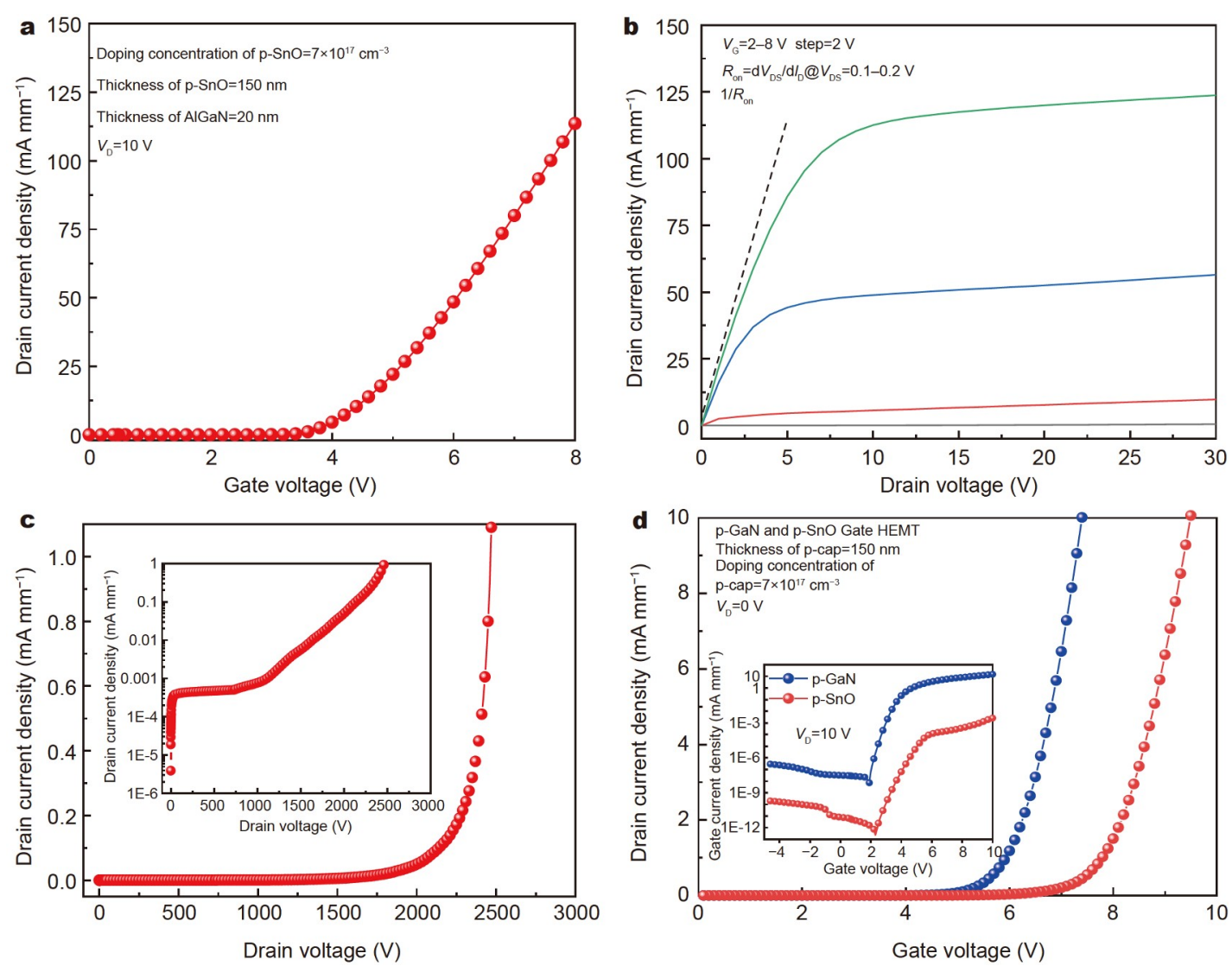

Figure 2 Simulated (a) transfer, (b) output, and (c) breakdown characteristics of the p-SnO gate cap HEMT; (d) gate leakage current density and gate breakdown characteristic of AlGaN/GaN HEMT with the $\mathrm{p}-\mathrm{SnO}$ or $\mathrm{p}-\mathrm{GaN}$ gate cap.

more electrons have been exhausted, in other words, the $E_{\mathrm{c}}$ of $\mathrm{GaN}$ at the $\mathrm{AlGaN} / \mathrm{GaN}$ interface will be far away from $E_{\mathrm{f}}$. Consequently, large $V_{\mathrm{G}}\left(V_{\mathrm{th}}\right)$ must be applied to open the 2DEG channel. Simultaneously, when the doping concentration is specified and the thickness of $\mathrm{SnO}$ increases from 50 to $150 \mathrm{~nm}$ (as shown in Fig. 3e), the depletion of 2DEG under the gate will be intensified and the operation of 2DEG channel must consume larger $V_{\mathrm{G}}$. In addition, in Fig. 3f, g, with the increase of doping concentration and thickness of $\mathrm{p}$-SnO cap, the gradually expanded depletion zone under the gate would induce the decreased gate leakage current density and increased gate breakdown voltage. This tendency is consistent with the changes of $V_{\text {th }}$, in other words, it is possible to achieve a large $V_{\text {th }}$ and high gate breakdown voltage at the same time.

\section{$V_{\text {th }}$ stability of p-SnO gate cap HEMT}

As the $\mathrm{SnO}$ film can be deposited by various process and treatment methods [36-39], the bandgap fluctuation of p-SnO film was unavoidable, which may also affect the device performance. As shown in Fig. 4a, the $V_{\text {th }}$ is nearly proportional to the bandgap, which coincides with the $V_{\text {th }}$ expression proposed in the previous literature [19]. Even at a low bandgap of $2.7 \mathrm{eV}$, the $V_{\text {th }}$ can also reach $2.3 \mathrm{~V}$. This insensitivity of $V_{\text {th }}$ to the bandgap fluctuation may enlarge the process window and enrich the deposition method selections for $\mathrm{p}-\mathrm{SnO}$ gate cap, which is desired to the cost-effective power electronics in the future.

Furthermore, the interface state between $\mathrm{p}-\mathrm{SnO}$ and $(\mathrm{Al}) \mathrm{GaN}$ is another factor affecting the device performance. According to the reports of $(\mathrm{Al}) \mathrm{GaN}$ MOS-HEMT, the polarity, energy level positions, and concentrations of interface traps may cause the instability of $V_{\text {th }}[40,41]$. Therefore, we assumed two defect levels $\left(E_{1}=E_{\mathrm{c}}-0.5 \mathrm{eV}, E_{2}=E_{\mathrm{v}}+0.5 \mathrm{eV}\right)$ and two defect densities $(1 \times$ $10^{13}$ and $\left.1 \times 10^{11} \mathrm{~cm}^{-2}\right)$ at the $\mathrm{p}-\mathrm{SnO} / \mathrm{AlGaN}$ interface. The two acceptor-like discrete states $\left(E_{\mathrm{A}}(\mathrm{H}), E_{\mathrm{A}}(\mathrm{L})\right)$ with different defect densities were placed at $E_{2}$, and two donor-like discrete states $\left(E_{\mathrm{D}}(\mathrm{H}), E_{\mathrm{D}}(\mathrm{L})\right)$ with different defect densities were placed at $E_{1}$. In order to simulate the influence of defects on $V_{\text {th }}$, the above four interface defects are introduced at $1 \mathrm{~nm}$ above and below the p-SnO/AlGaN interface. It is clear from Fig. $4 \mathrm{~b}$ that $V_{\text {th }}$ presents a negative drift (the donor state) or a positive drift (the acceptor state) behavior with respect to the ideal characteristics, and the higher the trap density, the greater the effect on $V_{\text {th }}$. It can be observed that the drift of $V_{\text {th }}$ is $0.2 \mathrm{~V}$ when the density is $1 \times 10^{11} \mathrm{~cm}^{-2}$, which reaches $3.4 \mathrm{~V}$ (positive drift) and $2.3 \mathrm{~V}$ (negative drift) at a density of $1 \times 10^{13} \mathrm{~cm}^{-2}$. Therefore, during the device fabrication, the interface defects should be reduced as much as possible to ensure good device performance. Also, when an acceptor trap at $E_{1}$ or a donor trap at $E_{2}$ is assumed, no changes in $V_{\text {th }}$ can be seen as the states are neutral in the voltage bias ranging from 0 to $10 \mathrm{~V}$, which agrees with the previous report [42]. Besides these inner defects, the outer factors may also affect the $V_{\text {th }}$ of device. For example, the water molecules adsorbed on the surface of the p-SnO film would produce additional charges by ionization and induce the changes of the $V_{\text {th }}$ at a bias of $V_{\mathrm{G}}$ [43], thus the device passivation is essential to improve the $V_{\text {th }}$ stability. In fact, the interface states are a very 


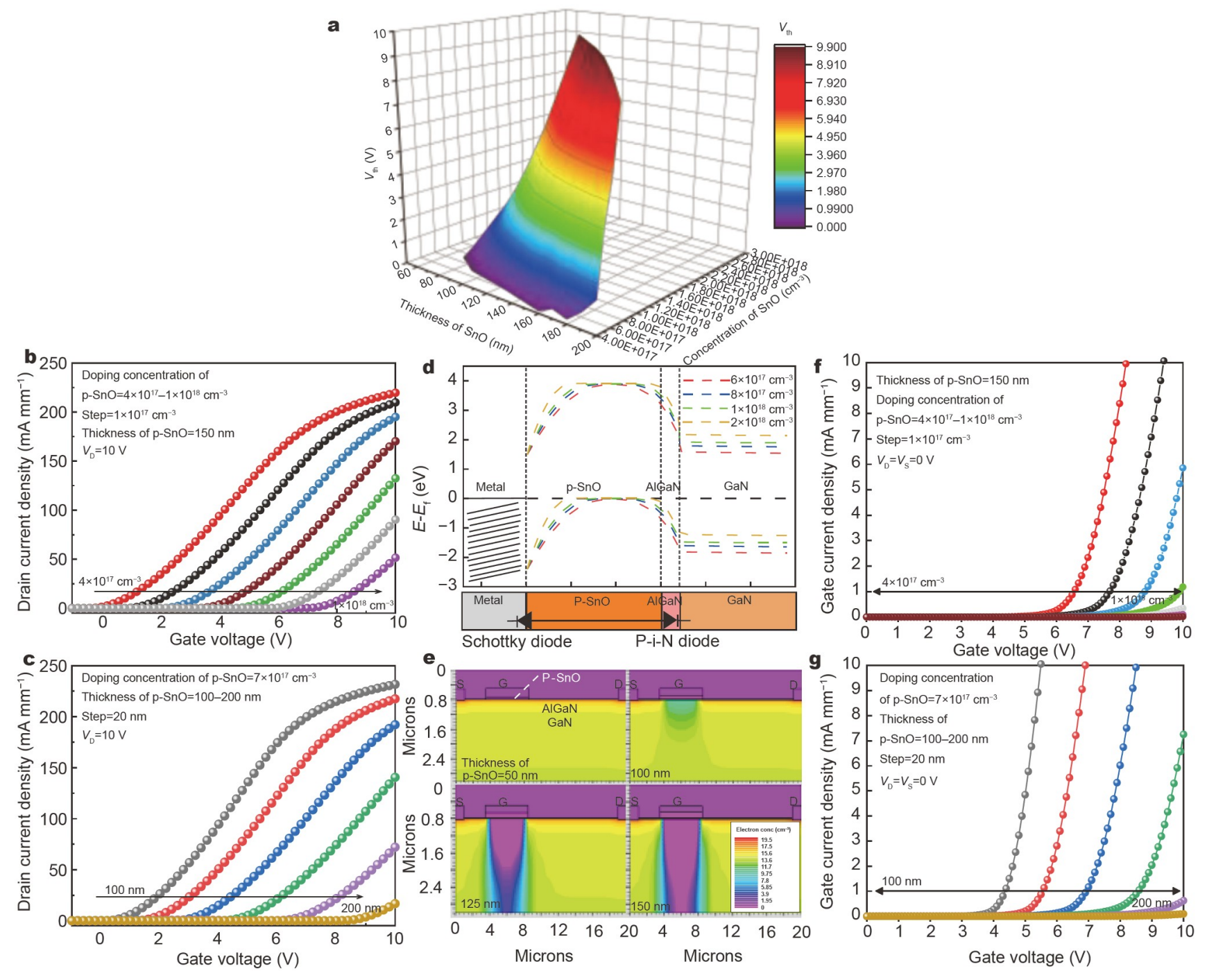

Figure 3 Dependence of simulated (a) $V_{\text {th }}$, (b, c) transfer characteristics, (d) energy band diagram, (e) electron concentration distributions, and (f) gate leakage current density on the p-SnO doping concentration and/or thickness for AlGaN/GaN HEMTs.
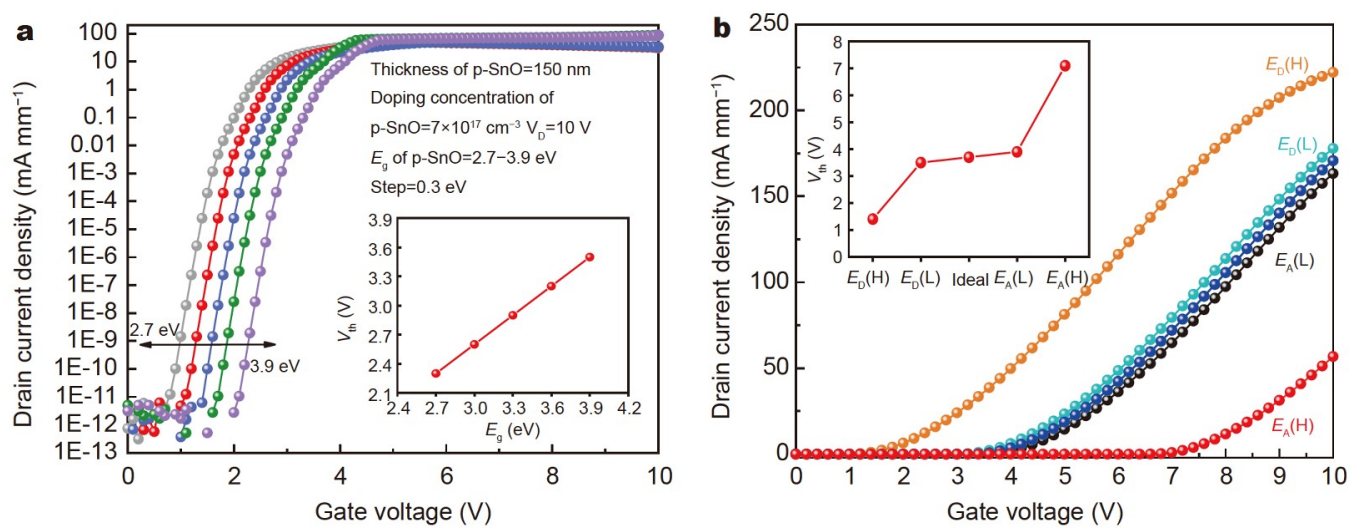

Figure 4 Simulated transfer characteristic curves of p-SnO gate cap HEMT (a) with various SnO bandgap values and (b) defects at SnO/AlGaN interface.

complex problem, and therefore more experimental studies should be carried out to understand the mechanism of $V_{\text {th }}$ stability beyond the simulations, which will be investigated in our next work.

\section{Experimental verification of $\mathbf{p}$-SnO gate cap HEMT}

The $\mathrm{p}$-SnO gate cap HEMT consists of a substrate layer (sapphire), a GaN semi-insulating layer, a 200-nm GaN channel layer, a $20-\mathrm{nm} \mathrm{Al}_{0.2} \mathrm{Ga}_{0.8} \mathrm{~N}$ barrier layer, and a 40-nm p-SnO 
layer. The $L_{\mathrm{GS}}, L_{\mathrm{G}}, W_{\mathrm{G}}$ and $L_{\mathrm{GD}}$ are $4,2,50$ and $12 \mu \mathrm{m}$, respectively. Fig. S1 presented the key process steps of AlGaN/GaN epitaxial growth and device fabrication. Here, the ohmic metal deposition and annealing $\left(850^{\circ} \mathrm{C}\right)$ were processed before the $\mathrm{p}$ $\mathrm{SnO}$ gate cap, as the phase of $\mathrm{SnO}$ is metastable and temperature-sensitive, the high temperature would accelerate the phase separation of $\mathrm{SnO}$ into metallic $\beta$-Sn-rich phase [44]. At the same time, considering limited temperature resistance of photoresist, the $40-\mathrm{nm}$ thick $\mathrm{SnO}$ layer was deposited by magnetron sputtering with $50 \mathrm{~W}$ radio-frequency power and 5.7 mTorr $(1 \mathrm{~m}$ Torr $=0.133 \mathrm{~Pa})$ growth pressure in $\mathrm{O}_{2} / \mathrm{Ar}+\mathrm{O}_{2}(3.1 \%)$ mixed atmosphere, followed by the lift-off process, and then the samples were annealed at $225^{\circ} \mathrm{C}$ in air to obtain the patterned pSnO cap layer. The X-ray diffraction (XRD, Fig. 5a and Fig. S2), optical bandgap (Fig. S3), and atomic force microscopy (AFM, Fig. 5b and Fig. S4) results of p-SnO film (on sapphire) from the same batch proved that the $\mathrm{p}-\mathrm{SnO}$ cap layer has been well formed. After the evaporation of gate metal (Ni/Au), the AlGaN/ GaN HEMTs with p-SnO gate cap were fabricated. Particularly, the room-temperature sputtering and low-temperature air annealing method for $\mathrm{p}$-SnO, proposed in our previous work [45], is perfectly compatible to the fabrication of GaN-based HEMTs. In addition, the metal gate HEMT has also been fabricated except for the $\mathrm{p}-\mathrm{SnO}$ cap deposition, and the corresponding electrical properties can be found in Fig. S5.

For $\mathrm{p}$-SnO gate cap HEMT, the measured transfer and output characteristics, gate leakage current density, gate and device breakdown curves are displayed in Fig. 5c-f. From the transfer characteristic curve, the $V_{\text {th }}$ of the p-SnO gate cap HEMT can reach $1 \mathrm{~V}$ and the E-mode operation has been realized. Compared with the metal gate HEMT, the $V_{\text {th }}$ was shifted forward by about $3 \mathrm{~V}$, which is superior to that of the experimentally reported HEMTs with the p-oxide $\left(\mathrm{NiO}, \mathrm{Cu}_{2} \mathrm{O}\right)$ gate caps $[14,29]$. Simultaneously, the p-SnO gate cap HEMT achieved a reverse gate leakage current density of $6 \times 10^{-6} \mathrm{~mA} \mathrm{~mm}^{-1}$ and a drain current density of $18 \mathrm{~mA} \mathrm{~mm}^{-1}$ when the $V_{\mathrm{G}}=4 \mathrm{~V}$, as shown in Fig. $5 \mathrm{c}$, d. Fig. $5 \mathrm{e}$, $\mathrm{f}$ show that the gate was broken down near $4.2 \mathrm{~V}\left(V_{\mathrm{D}}=0 \mathrm{~V}\right)$ and the device breakdown voltage reached $420 \mathrm{~V}$. According to the breakdown curves at $V_{\mathrm{G}}=0 \mathrm{~V}$ (Fig. 5f), the off-state leakage current at gate $\left(I_{\mathrm{G}}\right)$ is responsible for the device breakdown. Although the experimental results well verify the feasibility of $\mathrm{p}-\mathrm{SnO}$ as the gate cap of E-mode HEMT, the drain current density is still lower than that of the mainstream $\mathrm{p}-\mathrm{GaN}$ gate HEMTs. This can be partly explained by the transconductance characteristic in the inset of Fig. 5c. Although the transconductance value rapidly increased with the gate voltage (from 0 to $4 \mathrm{~V}$ ), the relatively low $V_{\mathrm{BG}}(4.2 \mathrm{~V})$ limited the possible improvement of drain current density. This is due to the first adoption of $\mathrm{p}$-SnO gate without optimization, and the quality of $\mathrm{p}-\mathrm{SnO}$ film, $\mathrm{SnO} /(\mathrm{Al}) \mathrm{GaN}$ interface, and metal contact needs to be further optimized. Therefore, more careful device designs and process adjustments would be performed in our future work to explore and improve the performance of $\mathrm{p}$ SnO gate cap HEMTs.

\section{Other p-type oxide gate cap HEMTs}

The typical p-type oxides, such as $\mathrm{Cu}_{2} \mathrm{O}, \mathrm{NiO}, \mathrm{WO}_{3}, \mathrm{MoO}_{3}$ and $\mathrm{V}_{2} \mathrm{O}_{5}$, have been selected as the p-type gate caps in the AlGaN/ GaN HEMTs to construct the E-mode devices.

Fig. 6a displays the energy band diagrams of various oxides and GaN. All the values are originated from the Refs. [14,29-32] and the structure parameters of devices are completely consistent. From the simulated transfer characteristic curves in Fig. 6b, the positive $V_{\text {th }}$ has been observed in all HEMTs with various oxide gate caps. It should be mentioned that the doping concentrations of $\mathrm{SnO}, \mathrm{WO}_{3}$ and $\mathrm{V}_{2} \mathrm{O}_{5}$ are $8 \times 10^{17} \mathrm{~cm}^{-3}$, and the $V_{\text {th }}$ of the corresponding devices are 4.0, 8.0 and $11 \mathrm{~V}$, respectively. Although the doping concentrations of $\mathrm{NiO}, \mathrm{Cu}_{2} \mathrm{O}$
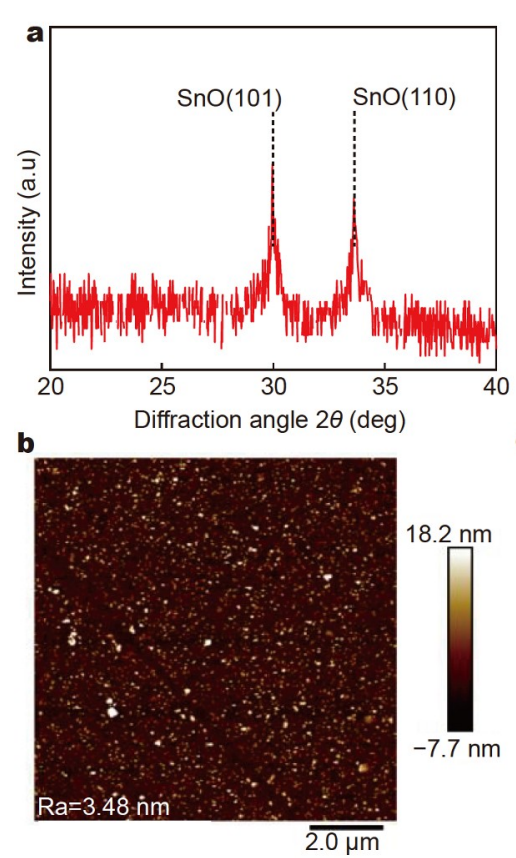
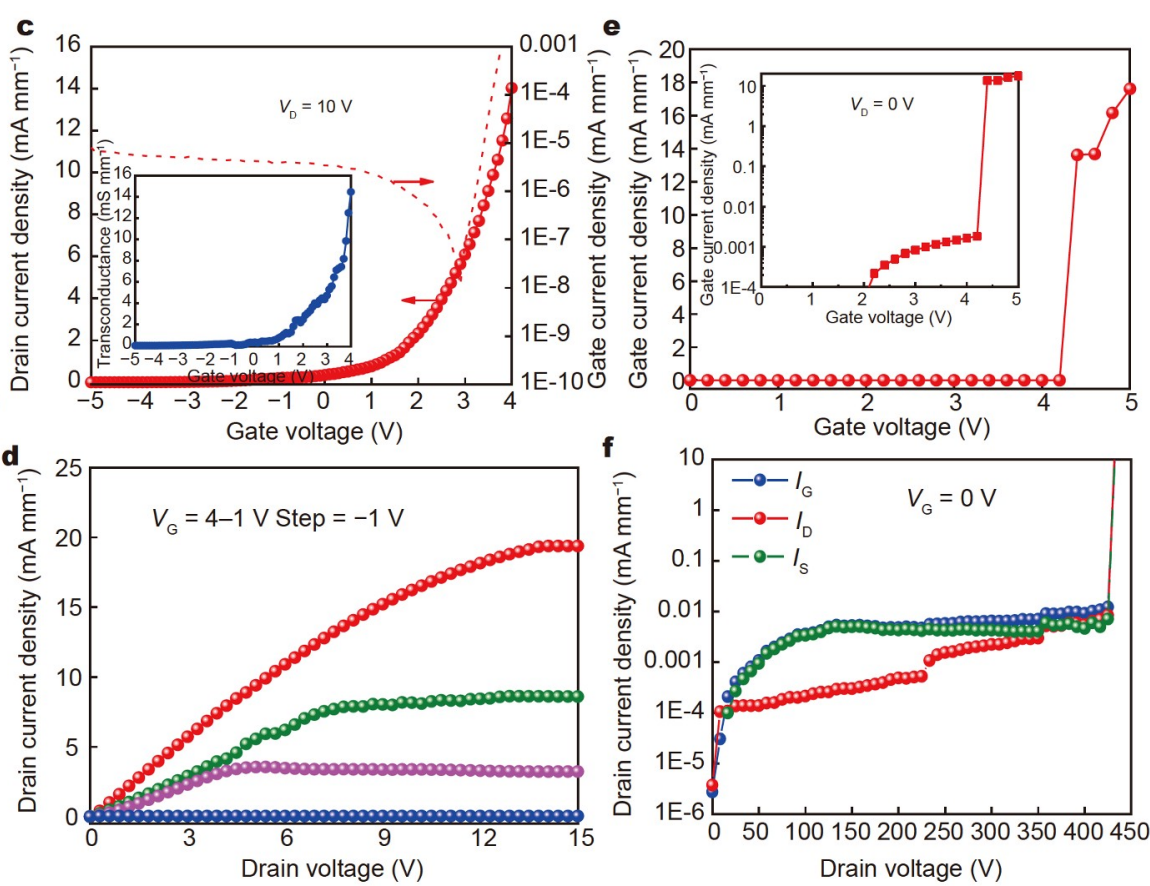

Figure 5 (a) X-ray diffraction pattern and (b) AFM image of p-SnO film on sapphire substrate; measured (c) transfer and transconductance characteristics, gate leakage current density, (d) output, (e) gate breakdown, and (f) device breakdown characteristics of p-SnO gate cap HEMT. Here the $I_{\mathrm{G}}, I_{\mathrm{D}}$ and $I_{\mathrm{S}}$ represented the off-state leakage current at gate, drain, and source, respectively. 

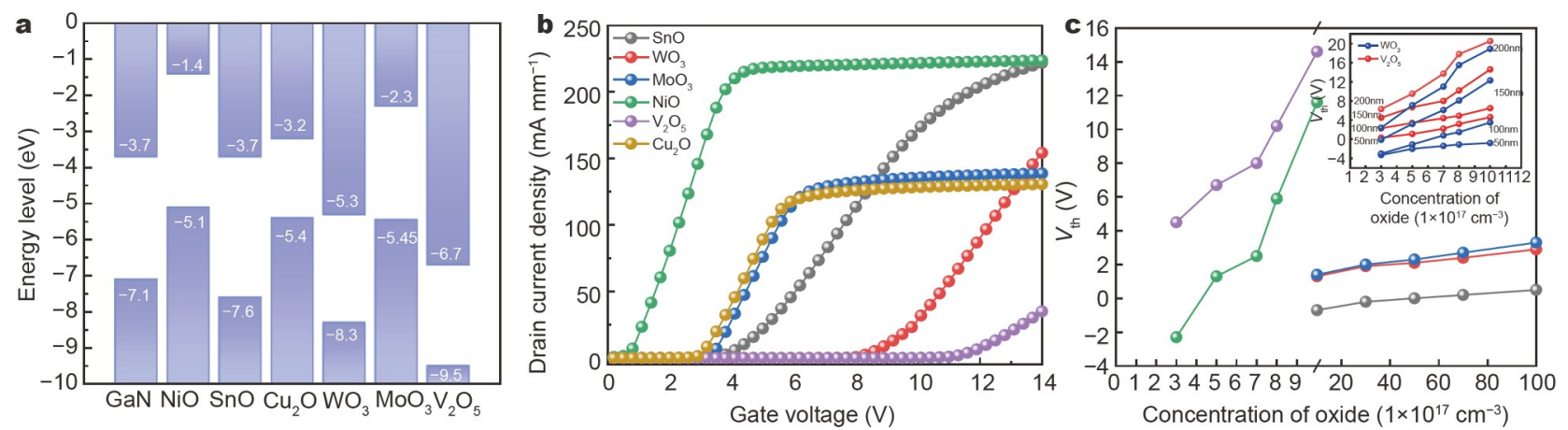

Figure 6 Simulated (a) energy band diagrams of p-type oxides and GaN, (b) transfer characteristic curves of p-type oxide gate cap HEMTs, and (c) threshold voltage regulation of $\mathrm{p}$-type oxide gate cap devices with different doping concentrations and thicknesses of p-type oxides.

and $\mathrm{MoO}_{3}$ are higher than $1 \times 10^{19} \mathrm{~cm}^{-3}$, the devices can only obtain a smaller $V_{\text {th. }}$. It is suggested that the deeper $E_{\mathrm{v}}$ of these oxides (Fig. 6a) make the main contribution to the more positive $V_{\text {th }}$, which can be proved by the theoretical formula of $V_{\text {th }}$ for $\mathrm{p}$ cap gate HEMT $[19,46]$ :

$V_{\mathrm{th}}=\frac{E_{\mathrm{gp}}+\Delta E_{\mathrm{c} 1}-\Delta E_{\mathrm{c} 2}}{q}+\frac{\delta_{\mathrm{b}}}{2 C_{\mathrm{b}}}+\frac{C_{\mathrm{th}}\left(E_{\mathrm{g}}-E_{\mathrm{a} 2}\right)}{C_{\mathrm{bq}}}-\frac{\delta_{\mathrm{p} 2}-\delta_{\mathrm{p} 1}}{C_{\mathrm{b}}}$.

According to the formula, the $V_{\text {th }}$ is determined by two parts, one is the $E_{\mathrm{v}}$-related part of $E_{\mathrm{c}, \mathrm{GaN}}-E_{\mathrm{v}, \mathrm{p} \text {-cap }}$, a value equals to $E_{\mathrm{gp}}$ $+\Delta E_{\mathrm{c} 1}-\Delta E_{\mathrm{c} 2}$, where $E_{\mathrm{gp}}$ is the bandgap of the p-cap layer, $\Delta E_{\mathrm{c} 1}$ is the $E_{\mathrm{c}}$ offset at the p-cap/AlGaN interface, $\Delta E_{\mathrm{c} 2}$ is the $E_{\mathrm{c}}$ offset at the $\mathrm{AlGaN} / \mathrm{GaN}$ interface. Another part is decided by the properties of $\mathrm{AlGaN} / \mathrm{GaN}$ heterostructure. In consequent, the deeper $E_{\mathrm{v}}$ of $\mathrm{p}$-cap material is, the greater value of $E_{\mathrm{c}, \mathrm{GaN}}-$ $E_{\mathrm{v}, \mathrm{p} \text {-cap }}$, and the greater $V_{\text {th }}$ will be obtained. This is well consistent with the changes of $V_{\text {th }}$ in HEMTs (Fig. 6b) with different p-oxide gate caps possessing various $E_{\mathrm{v}}$ levels.

Additionally, it can be observed from Fig. $6 \mathrm{c}$ that the $V_{\text {th }}$ of HEMTs with p-type $\mathrm{WO}_{3}$ and $\mathrm{V}_{2} \mathrm{O}_{5}$ gate caps could be easily wide-range-adjusted by controlling the doping concentration, while the $V_{\text {th }}$ values of devices with p-type $\mathrm{NiO}, \mathrm{Cu}_{2} \mathrm{O}$, and $\mathrm{MoO}_{3}$ gate caps are much smaller even at a high doping concentration of $1 \times 10^{19} \mathrm{~cm}^{-3}$. Besides the doping levels, the thickness of $\mathrm{WO}_{3}$ and $\mathrm{V}_{2} \mathrm{O}_{5}$ gate caps can also be used to adjust the $V_{\text {th }}$ (inset in Fig. 6c), and the relatively high $V_{\text {th }}$ of $\mathrm{V}_{2} \mathrm{O}_{5}$ gate cap device can be attributed to its deeper $E_{\mathrm{v}}$ and stronger band uplift ability at the AlGaN/GaN interface. All of these confirm that the $E_{\mathrm{v}}$ depth of wide-bandgap p-oxides plays the crucial role in depleting the 2DEG at the AlGaN/GaN interface, and the Emode AlGaN/GaN HEMTs are achievable by carefully controlling the doping concentration and thickness of $\mathrm{p}$-oxide gate caps.

\section{CONCLUSION}

The $V_{\text {th }}$ of AlGaN/GaN HEMT with $\mathrm{p}$-SnO gate cap can be wide-range-controlled from zero to positive $10 \mathrm{~V}$ by simply adjusting the thickness or the doping concentration of $\mathrm{p}-\mathrm{SnO}$ layer. In simulations, the device demonstrates a drain current density above $120 \mathrm{~mA} \mathrm{~mm}^{-1}$, a $V_{\mathrm{BG}}$ of $7.5 \mathrm{~V}$, and $V_{\mathrm{B}}$ over $2 \mathrm{kV}$. It has been suggested that the p-oxides with wide bandgap and deep $E_{\mathrm{v}}$ are promising gate cap selections for E-mode devices. Furthermore, the experimental AlGaN/GaN HEMT with the sputtered $\mathrm{p}-\mathrm{SnO}$ gate cap achieved a positive $V_{\text {th }}$ of $1 \mathrm{~V}, V_{\mathrm{BG}}$ of $4.2 \mathrm{~V}$ and $V_{\mathrm{B}}$ of $420 \mathrm{~V}$, which further verify the feasibility of p-
$\mathrm{SnO}$ as the gate cap of E-mode HEMT. This work is instructive to the design and manufacture of cost-effective $\mathrm{GaN}$ power electronic devices.

\section{Received 10 August 2021; accepted 21 October 2021;} published online 15 December 2021

1 Kanamura M, Kikkawa T, Iwai T, et al. An over $100 \mathrm{~W}$ n-GaN/nAlGaN/GaN MIS-HEMT power amplifier for wireless base station applications. In: IEEE International Electron Devices Meeting, 2005. IEDM Technical Digest. Washington, 2005. 572-575

2 Liu J, Zhou Y, Chu R, et al. Highly linear $\mathrm{Al}_{0.3} \mathrm{Ga}_{0.7} \mathrm{~N}-\mathrm{Al}_{0.05} / \mathrm{Ga}_{0.95} / \mathrm{N}-$ GaN composite-channel HEMTs. IEEE Electron Device Lett, 2005, 26: 145-147

3 Wurfl J, Hilt O, Bahat-Treidel E, et al. Technological approaches towards high voltage, fast switching GaN power transistors. ECS Trans, 2013, 52: 979-989

4 Oka T, Nozawa T. AlGaN/GaN recessed MIS-Gate HFET with highthreshold-voltage normally-off operation for power electronics applications. IEEE Electron Device Lett, 2008, 29: 668-670

5 Cai Y, Zhou Y, Lau KM, et al. Control of threshold voltage of AlGaN/ GaN HEMTs by fluoride-based plasma treatment: From depletion mode to enhancement mode. IEEE Trans Electron Devices, 2006, 53: 2207-2215

6 Hu X, Simin G, Yang J, et al. Enhancement mode AlGaN/GaN HFET with selectively grown pn junction gate. Electron Lett, 2000, 36: 753754

7 Tsuyukuchi N, Nagamatsu K, Hirose Y, et al. Low-leakage-current enhancement-mode $\mathrm{AlGaN} / \mathrm{GaN}$ heterostructure field-effect transistor using p-type gate contact. Jpn J Appl Phys, 2006, 45: 319-321

8 Sugiyama $\mathrm{T}$, Amano $\mathrm{H}$, Iida $\mathrm{D}$, et al. High-temperature operation of normally off-mode AlGaN/GaN heterostructure field-effect transistors with p-GaN gate. Jpn J Appl Phys, 2011, 50: 01AD03

9 Hwang I, Choi H, Lee JW, et al. $1.6 \mathrm{kV}, 2.9 \mathrm{~m} \Omega \mathrm{cm}^{2}$ normally-off pGaN HEMT device. In: 2012 24th International Symposium on Power Semiconductor Devices and ICs. Bruges, 2012. 41-44

10 Hwang I, Kim J, Choi HS, et al. p-GaN gate HEMTs with tungsten gate metal for high threshold voltage and low gate current. IEEE Electron Device Lett, 2013, 34: 202-204

11 Zhang J, Zhang W, Wu Y, et al. Wafer-scale Si-GaN monolithic integrated E-mode cascode FET realized by transfer printing and selfaligned etching technology. IEEE Trans Electron Devices, 2020, 67: 3304-3308

12 Erofeev EV, Kagadei VA, Kazimirov AI, et al. High threshold voltage pgate GaN transistors. In: 2015 International Siberian Conference on Control and Communications (SIBCON). Omsk, 2015. 1-4

13 Han Y, Xue S, Guo W, et al. Highly selective dry etching of GaN over AlGaN using inductively coupled $\mathrm{Cl}_{2} / \mathrm{N}_{2} / \mathrm{O}_{2}$ plasmas. Jpn J Appl Phys, 2003, 42: L1139-L1141

14 Wang L, Li L, Xie T, et al. Threshold voltage tuning in AlGaN/GaN 
HFETs with p-type $\mathrm{Cu}_{2} \mathrm{O}$ gate synthesized by magnetron reactive sputtering. Appl Surf Sci, 2018, 437: 98-102

15 Suzuki A, Choe S, Yamada $\mathrm{Y}$, et al. $\mathrm{NiO}$ gate GaN-based enhancementmode hetrojunction field-effect transistor with extremely low on-resistance using metal organic chemical vapor deposition regrown $\mathrm{Ge}-$ doped layer. Jpn J Appl Phys, 2016, 55: 121001

16 Zhang T, Wang L, Li X, et al. Positive threshold voltage shift in AlGaN/ GaN HEMTs with p-type $\mathrm{NiO}$ gate synthesized by magnetron reactive sputtering. Appl Surf Sci, 2018, 462: 799-803

17 Huang SJ, Chou CW, Su YK, et al. Achievement of normally-off Al$\mathrm{GaN} / \mathrm{GaN}$ high-electron mobility transistor with $\mathrm{p}-\mathrm{NiO}_{x}$ capping layer by sputtering and post-annealing. Appl Surf Sci, 2017, 401: 373-377

18 Kaneko N, Machida O, Yanagihara M, et al. Normally-off AlGaN/GaN HFETs using $\mathrm{NiO}_{x}$ gate with recess. In: 2009 21st International Symposium on Power Semiconductor Devices \& IC's. Barcelona, 2019. 25 28

19 Li G, Li X, Zhao J, et al. Design principle for a p-type oxide gate layer on $\mathrm{AlGaN} / \mathrm{GaN}$ toward normally-off HEMTs: Li-doped $\mathrm{NiO}$ as a model. J Mater Chem C, 2020, 8: 1125-1134

20 Quackenbush NF, Allen JP, Scanlon DO, et al. Origin of the bipolar doping behavior of SnO from X-ray spectroscopy and density functional theory. Chem Mater, 2013, 25: 3114-3123

21 Ogo Y, Hiramatsu H, Nomura K, et al. p-Channel thin-film transistor using p-type oxide semiconductor, SnO. Appl Phys Lett, 2008, 93: 032113

22 Liang LY, Liu ZM, Cao HT, et al. Microstructural, optical, and electrical properties of $\mathrm{SnO}$ thin films prepared on quartz via a two-step method. ACS Appl Mater Interfaces, 2010, 2: 1060-1065

23 Lee HN, Kim HJ, Kim CK. p-Channel tin monoxide thin film transistor fabricated by vacuum thermal evaporation. Jpn J Appl Phys, 2010, 49: 020202

24 Fortunato E, Barros R, Barquinha $\mathrm{P}$, et al. Transparent p-type $\mathrm{SnO}_{x}$ thin film transistors produced by reactive RF magnetron sputtering followed by low temperature annealing. Appl Phys Lett, 2010, 97: 052105

25 Li X, Liang L, Cao H, et al. Determination of some basic physical parameters of $\mathrm{SnO}$ based on $\mathrm{SnO} / \mathrm{Si}$ pn heterojunctions. Appl Phys Lett, 2015, 106: 132102

26 Li Y, Yang J, Wang Y, et al. Complementary integrated circuits based on p-type $\mathrm{SnO}$ and n-type IGZO thin-film transistors. IEEE Electron Device Lett, 2018, 39: 208-211

27 Uemoto Y, Hikita M, Ueno H, et al. Gate injection transistor (GIT) - A normally-off $\mathrm{AlGaN} / \mathrm{GaN}$ power transistor using conductivity modulation. IEEE Trans Electron Devices, 2007, 54: 3393-3399

28 Liu S, Song X, Zhang J, et al. Comprehensive design of device parameters for GaN vertical trench MOSFETs. IEEE Access, 2020, 8: 5712657135

29 Li L, Wang W, He L, et al. Synthesis and characterization of p-type $\mathrm{NiO}$ films suitable for normally-off AlGaN/GaN HFETs application. Mater Sci Semicond Process, 2017, 67: 141-146

30 Chen CC, Chang WH, Yoshimura K, et al. An efficient triple-junction polymer solar cell having a power conversion efficiency exceeding $11 \%$. Adv Mater, 2014, 26: 5670-5677

31 Erre R, Legay MH, Fripiat JJ. Reaction of molecular hydrogen with the 100 face of $\mathrm{MoO}_{3}$. Surf Sci, 1983, 127: 69-82

32 Zhang TN, Wang SX, Wei W, et al. Atomic-Layer-Deposited ultrathin films of vanadium pentoxide crystalline nanoflakes with controllable thickness and optical band-gap. J Infrared Millim W, 2019, 38: 1-7

33 Iwata N, Kondo T. High-selectivity dry etching for p-type GaN gate formation of normally-off operation high-electron-mobility transistor. Jpn J Appl Phys, 2021, 60: SAAD01

34 Zhao SL, Wang ZZ, Chen DZ, et al. $1.8-\mathrm{kV}$ circular AlGaN/GaN/AlGaN double-heterostructure high electron mobility transistor. Chin Phys B, 2019, 28: 027301

$35 \mathrm{Xu} \mathrm{N}, \mathrm{Hao} \mathrm{R}$, Chen $\mathrm{F}$, et al. Gate leakage mechanisms in normally off pGaN/AlGaN/GaN high electron mobility transistors. Appl Phys Lett, 2018, 113: 152104

36 Du J, Xia C, Liu Y, et al. Electronic characteristics of p-type transparent SnO monolayer with high carrier mobility. Appl Surf Sci, 2017, 401: 114-119
37 Guzmán-Caballero DE, Quevedo-López MA, Ramírez-Bon R. Optical properties of p-type $\mathrm{SnO}_{x}$ thin films deposited by DC reactive sputtering. J Mater Sci-Mater Electron, 2019, 30: 1366-1373

38 Sivaramasubramaniam R, Muhamad MR, Radhakrishna S. Optical properties of annealed tin(II) oxide in different ambients. Phys Stat Sol A, 1993, 136: 215-222

39 Guo W, Fu L, Zhang Y, et al. Microstructure, optical, and electrical properties of p-type SnO thin films. Appl Phys Lett, 2010, 96: 042113

40 Ťapajna M, Kuzmík J. A comprehensive analytical model for threshold voltage calculation in $\mathrm{GaN}$ based metal-oxide-semiconductor highelectron-mobility transistors. Appl Phys Lett, 2012, 100: 113509

41 Irokawa $\mathrm{Y}$, Nabatame $\mathrm{T}$, Yuge $\mathrm{K}$, et al. Investigation of $\mathrm{Al}_{2} \mathrm{O}_{3} / \mathrm{GaN}$ interface properties by sub-bandgap photo-assisted capacitance-voltage technique. AIP Adv, 2019, 9: 085319

42 Miczek M, Mizue C, Hashizume T, et al. Effects of interface states and temperature on the $C-V$ behavior of metal/insulator/AlGaN/GaN heterostructure capacitors. J Appl Phys, 2008, 103: 104510

43 Qu Y, Yang J, Li Y, et al. Organic and inorganic passivation of p-type $\mathrm{SnO}$ thin-film transistors with different active layer thicknesses. Semicond Sci Technol, 2018, 33: 075001

44 Fortunato E, Barquinha P, Martins R. Oxide semiconductor thin-film transistors: A review of recent advances. Adv Mater, 2012, 24: 29452986

45 Li Y, Yang J, Qu Y, et al. Ambipolar $\mathrm{SnO}_{x}$ thin-film transistors achieved at high sputtering power. Appl Phys Lett, 2018, 112: 182102

46 Bakeroot B, Stockman A, Posthuma N, et al. Analytical model for the threshold voltage of $\mathrm{p}-(\mathrm{Al}) \mathrm{GaN}$ high-electron-mobility transistors. IEEE Trans Electron Devices, 2018, 65: 79-86

Acknowledgements This work was supported by the National Natural Science Foundation of China (62003151, 61925404, 62074122, and 61904139) and the Key Research and Development Program in Shaanxi Province (2016KTZDGY-03-01)

Author contributions Chen D conceived the idea, designed and guided the simulation calculation and experiment. Yuan P completed most of the calculations and experiments, and wrote the manuscript under Chen D's guidance. Yan S deposited the p-SnO film under the guidance of Xin Q. Chen D and Zhao $\mathrm{S}$ revised the manuscript. Zhang $\mathrm{Y}$ and Zhang $\mathrm{C}$ contributed to the epitaxial growth of AlGaN/GaN structure and device fabrication. Liu S, Song X, Zhang J, Zhang W, Zhu W, Xi H, and Zhou H helped with the model calibration, device measurement, film characterization, and data analysis. Zhang J and Hao Y supervised the group. All authors read and approved the manuscript.

Conflict of interest The authors declare that they have no conflict of interest.

Supplementary information Experimental details and supporting data are available in the online version of this paper.

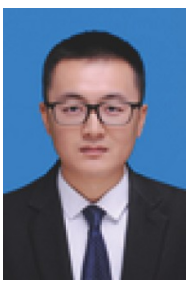

Peng Yuan received his bachelor degree in microelectronics science and engineering from Xidian University in 2019. Now, he is a graduate student in Prof. Chen's group. His current research interests are concentrating on GaN power electronic devices. 


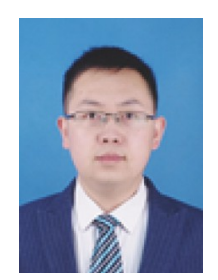

Dazheng Chen obtained his $\mathrm{BE}$ and $\mathrm{PhD}$ degrees from Xidian University in 2010 and 2015, respectively, and entered the Post-doctoral Research Station of Physics in 2016. In 2018, he joined the School of Microelectronics, Xidian University, and is now an associate professor at the School of Microelectronics. His research interests focus on wide-bandgap semiconductor power devices and photoelectric devices.

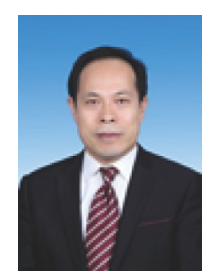

Jincheng Zhang (Member, IEEE) received the MS and $\mathrm{PhD}$ degrees from Xidian University, Xi'an, China, in 2001 and 2004 , respectively. He is currently a professor at $\mathrm{Xi}-$ dian University, Xi'an. His current interests include widebandgap semiconductor $\mathrm{GaN}$ and diamond materials and devices.

\section{基于p-SnO帽层栅的高阈值增强型 $\mathrm{AlGaN} / \mathrm{GaN}$ HEMTs}

陈大正 ${ }^{1 \dagger *}$, 袁鹏 ${ }^{1 \dagger}$, 赵胜雷 ${ }^{1}$, 刘爽 ${ }^{1}$, 辛倩 ${ }^{2}$, 宋秀峰 ${ }^{1}$, 颜世琪 ${ }^{2}$,

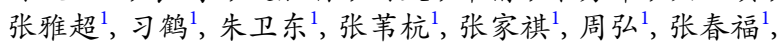
张进成 ${ }^{*}$, 郝跃 ${ }^{1}$

摘要 目前, p-GaN帽层技术是实现增强型 $\mathrm{GaN}$ 基HEMT的主流商用技 术, 但 $\mathrm{Mg}$ 掺杂难激活以及刻蚀损伤等因素限制了器件性能的进一步提 升, 因此高性能、低成本的增强型帽层技术具有重要的研究意义. 本文 采用 $\mathrm{p}$ 型氧化亚锡 $(\mathrm{p}-\mathrm{SnO}$ ) 代替 $\mathrm{p}-\mathrm{GaN}$ 作为胁帽层引入 $\mathrm{AlGaN} / \mathrm{GaN}$ HEMT, 并通过Silvaco 器件仿真和实验验证两方面系统研究了器件的 电学性能. 仿真结果显示, 通过简单改变p-SnO的厚度 $(50-200 \mathrm{~nm}$ )或掺 杂浓度 $\left(3 \times 10^{17}-3 \times 10^{18} \mathrm{~cm}^{-3}\right)$, 可以实现器件國值电压在 $0-10 \mathrm{~V}$ 范围 内连续可调, 同时器件的漏极电流密度超过 $120 \mathrm{~mA} \mathrm{~mm}^{-1}$, 栅击穿和器 件击穿电压分别达到7.5和 $2470 \mathrm{~V}$. 在此基础上, 我们实验制备了基于磁 控溅射p-SnO帽层的AlGaN/GaN HEMT, 未经优化的器件测得了 $1 \mathrm{~V}$ 的 阈值电压、 $4.2 \mathrm{~V}$ 的栅击穿电压和 $420 \mathrm{~V}$ 的器件击穿电压, 证实了 $\mathrm{p}-\mathrm{SnO}$ 薄膜作为增强型 $\mathrm{GaN}$ 基HEMT栅帽层的应用潜力, 为进一步提升增强 型AlGaN/GaN HEMT性能, 同时降低成本奠定了基础. 